\title{
Anesthesia for a patient with morbid obesity using dexmedetomidine without narcotics
}

\author{
[L'anesthésie chez un patient obèse morbide avec la dexmédétomidine
}

sans narcotiques]

Roger E. Hofer MD, ${ }^{*}$ Juraj Sprung MD PhD, ${ }^{*}$ Michael G. Sarr MD, $†$ Denise J. Wedel MD*

Purpose: To describe the anesthetic management of a patient with extreme obesity undergoing bariatric surgery whose intraoperative narcotic management was entirely substituted with dexmedetomidine.

Clinical features: We describe a 433-kg morbidly obese patient with obstructive sleep apnea and pulmonary hypertension who underwent Roux-en-Y gastric bypass. Because of the concern that the use of narcotics might cause postoperative respiratory depression, we substituted their intraoperative use with a continuous infusion of dexmedetomidine $\left(0.7 \mu \mathrm{g} \cdot \mathrm{kg}^{-1} \cdot \mathrm{hr}^{-1}\right)$. The anesthesia course was uneventful, and the intraoperative use of dexmedetomidine was associated with low anesthetic requirements ( 0.5 minimum alveolar concentration). After completion of the operation and after tracheal extubation, the dexmedetomidine infusion was continued uninterrupted throughout the end of the first postoperative day. The analgesic effects of dexmedetomidine extended narcotic-sparing effects into the postoperative period; the patient had lower narcotic requirements during the first postoperative day [48 $\mathrm{mg}$ of morphine by patient-controlled analgesia (PCA)] while still receiving dexmedetomidine, compared to the second postoperative day (morphine $148 \mathrm{mg}$ by PCA) with similar pain scores.

Conclusion: Dexmedetomidine may be a useful anesthetic adjunct for patients who are susceptible to narcotic-induced respiratory depression. In this morbidly obese patient the narcotic-sparing effects of dexmedetomidine were evident both intraoperatively and postoperatively.
Objectif : Décrire la démarche anesthésique utilisée chez un patient atteint d'obésité morbide devant subir un pontage gastrique. Les narcotiques peropératoires ont été entièrement remplacés par la dexmédétomidine.

Éléments cliniques : Le patient pesait $433 \mathrm{~kg}$, présentait une apnée du sommeil obstructive et de l'hypertension pulmonaire. II devait subir un pontage gastrique de Roux-en-Y. Inquiets de causer une dépression respiratoire postopératoire en utilisant des narcotiques, nous avons substitué leur usage peropératoire par une perfusion continue de dexmédétomidine $\left(0,7 \mu \mathrm{g} \cdot \mathrm{kg}^{-1} \cdot \mathrm{h}^{-1}\right)$. L'anesthésie s'est bien déroulée et l'usage peropératoire de dexmédétomidine a été associé à de faibles demandes d'anesthésiques (concentration alvéolaire minimale de 0,5). Après l'opération et l'extubation endotrachéale, la perfusion continue de dexmédétomidine a été poursuivie jusqu'à la fin du premier jour postopératoire. La dexmédétomidine a permis d'économiser aussi les narcotiques après l'opération ; le patient a demandé moins de narcotiques pendant le premier jour postopératoire [48 mg de morphine en analgésie autocontrôlée (AAC)] tout en recevant la dexmédétomidine, comparativement au deuxième jour (I 48 mg de morphine en AAC). Les scores de douleur étaient comparables.

Conclusion : La dexmédétomidine peut être un ajout anesthésique utile chez les patients susceptibles de dépression respiratoire induite par les narcotiques. Les effets d'économie de narcotiques de la dexmédétomidine ont été évidents ici pendant et après l'opération.

HE increasing incidence of morbid obesity
is a crisis in national healthcare, which has
precipitated an increase in bariatric surgery.
Morbid obesity is associated with marked respiratory co-morbidities such as obstructive sleep apnea (OSA) and/or pulmonary hypertension that may have a profound impact on anesthetic manage-

From the Departments of Anesthesiology, ${ }^{*}$ and Surgery, $†$ Mayo Clinic College of Medicine, Mayo Clinic, Rochester, Minnesota, USA. Address correspondence to: Dr. Juraj Sprung, Mayo Clinic College of Medicine, Department of Anesthesiology, Mayo Clinic, 200 First Street S.W., Rochester, Minnesota 55905, USA. Phone: 507-255-3298; Fax: 507-255-6463; E-mail: sprung.juraj@mayo.edu Support for this report is provided from the Department of Anesthesiology, Mayo Clinic, Rochester, Minnesota, USA.

Assessed May 25, 2004.

Accepted for publication July 29, 2004.

Revision accepted November 8, 2004. 
ment. Sugerman ${ }^{1}$ demonstrated that surgically induced weight loss after bariatric surgery markedly improved numerous markers of respiratory insufficiency [i.e., arterial oxygenation, carbon dioxide $\left.\left(\mathrm{CO}_{2}\right)\right]$ retention, frequency of apnea, lung volume, and polycythemia). Therefore, respiratory co-morbidities of morbid obesity should be considered an important indication for an aggressive approach to weight reduction. We describe a $433-\mathrm{kg}$ morbidly obese patient complicated by OSA and pulmonary hypertension, who underwent Roux-en-Y gastric bypass. The patient refused preoperative epidural placement for pain management. Because of concern that opioids might cause perioperative respiratory depression, we substituted the intraoperative use of narcotics with dexmedetomidine, a highly selective $\alpha_{2}{ }^{-}$ adrenergic agonist with hypnotic, sedative, sympatholytic, and analgesic properties. ${ }^{2}$ Because dexmedetomidine does not cause respiratory depression, and patients can be easily aroused, it may be used even after tracheal extubation. ${ }^{3,4}$

\section{Clinical features}

A 42-yr-old male with extreme obesity (height $198 \mathrm{~cm}$, weight $433 \mathrm{~kg}$, body mass index $110 \mathrm{~kg} \cdot \mathrm{m}^{-2}$ ) was admitted for bariatric surgery. He had been hospitalized and bedridden over the past ten months because of an inability to perform basic daily activities. His obesity was complicated with OSA, pulmonary hypertension, massive lower extremity lymphedema, and gastroesophageal reflux. The preoperative electrocardiogram showed a normal sinus rhythm with non specific ST-T wave abnormalities. Chest radiography was normal; results of pulmonary function tests showed a severe restrictive pattern: forced vital capacity (FVC) of $2 \mathrm{~L}=$ $31 \%$ predicted; forced expiratory volume in one second $\left(\mathrm{FEV}_{1}\right)$ was $1.2 \mathrm{~L} \cdot \mathrm{min}^{-1}=24 \%$ predicted, $\mathrm{FEV}_{1} / \mathrm{FVC}$ $60 \%$ ). Arterial blood gases on room air were: $\mathrm{pHa} 7.39$, arterial partial oxygen tension $\left(\mathrm{PaO}_{2}\right) 69 \mathrm{mmHg}$; oxyhemoglobin saturation $\left(\mathrm{SaO}_{2}\right) 91 \%$, bicarbonate 30 $\mathrm{mEq} \cdot \mathrm{L}^{-1}$, and arterial partial $\mathrm{CO}_{2}$ tension $\left(\mathrm{PaCO}_{2}\right) 5 \mathrm{l}$ $\mathrm{mmHg}$. All other laboratory values were within normal limits. Transthoracic echocardiography (described as technically challenging with suboptimal images) revealed normal left ventricular size with normal global systolic function (estimated ejection fraction 60\%). The right ventricle was mildly enlarged, however the cardiologist was unable to estimate right ventricular systolic pressure. The rest of the examination appeared within normal limits. Preoperative oral medications included ranitidine $150 \mathrm{mg}$ three times daily, trazodone $50 \mathrm{mg}$ every evening, zolpidem $100 \mathrm{mg}$ daily, ibuprofen 400 mg three times daily, albuterol/ipratropium inhaler as needed, and oxycodone $40 \mathrm{mg}$, three times daily. In addition, he was receiving heparin 10,000 units subcutaneously three times daily. Polysomnography confirmed severe, rapid eye movement-dependent OSA syndrome. A trial of continuous positive airway pressure (CPAP) by mask was attempted, but the patient did not tolerate it.

The morning of the operation the patient was positioned on two side-by-side heavy-duty operating room tables (Skytron Hercules 6500HD, Grand Rapids, MI, USA), clamped together in $10^{\circ}$ reverse Trendelenburg position. A patient lift system mattress (A.I.R. PAL Patient Lift, LCI Medical Inc, Nilfisk, Denmark) was used to transfer the patient from the heavy-duty transport cart to the operating room table. The patient refused epidural placement for perioperative analgesia. Intravenous glycopyrrolate $(0.2 \mathrm{mg})$, midazolam (4 $\mathrm{mg})$, ketamine $(60 \mathrm{mg})$, and topical lidocaine were used for an uneventful fibreoptic tracheal intubation (the patient's airway was assessed as "not difficult," but despite that assessment, fibreoptic intubation was performed electively primarily due to the patient's size). After identification of exhaled $\mathrm{CO}_{2}$ by mass spectrometry, general anesthesia was induced with $i v$ propofol $200 \mathrm{mg}$ and initial muscle relaxation was achieved with $10 \mathrm{mg}$ of vecuronium $i v$. The patient's lungs were ventilated with a tidal volume (TV) of $1200 \mathrm{~mL}, 10$ breaths. $\mathrm{min}^{-1}, 10 \mathrm{~cm} \mathrm{H}_{2} \mathrm{O}$ of positive end-expiratory pressure (PEEP), using $\mathrm{FIO}_{2}$ of 0.6; the peak inspiratory pressure (PIP) was $38 \mathrm{~cm} \mathrm{H}_{2} \mathrm{O}$. Isoflurane was administered at an end-tidal concentration of $0.9 \%$. A right subclavian, four-lumen central venous catheter was placed without difficulty (initial central venous pressure was $19 \mathrm{mmHg}$ ). Immediately after anesthetic induction, we initiated the administration of iv dexmedetomidine: $1.4 \mu \mathrm{g} \cdot \mathrm{kg}^{-1}$ as a loading dose (Precedex, Abbot Laboratories Inc., Abbot Park, IL, USA) over ten minutes (dosing weight was based on an estimated lean body mass of $175 \mathrm{~kg}$ ) followed by a continuous infusion of $0.7 \mu \mathrm{g} \cdot \mathrm{kg}^{-1} \cdot \mathrm{hr}^{-1}$. This rate was maintained uninterrupted throughout the operation until the end of the first postoperative day. No narcotics were given pre- or intraoperatively.

After anesthetic induction, we inserted a kink resistant polyurethane right radial artery catheter (Cook Pressure Monitoring Catheter, Cook, Critical Care, Bloomington, IN, USA). We used a continuous blood gas-monitoring system (Trend Care Satellite TMC 6000, Diametrics Medical LTD., Buckinghamshire, England, UK), with a thin electrode inserted through the existing arterial line, to continuously monitor $\mathrm{PaO}_{2}$, $\mathrm{PaCO}_{2}$ and $\mathrm{pH}$. Hemodynamics and cardiac function were monitored continuously with transesophageal 
echocardiography; an initial examination revealed normal left ventricular systolic function and a calculated cardiac output of $9.6 \mathrm{~L} \cdot \mathrm{min}^{-1}$. The right ventricle was moderately enlarged with a moderate decrease in systolic function and an estimated pulmonary artery systolic pressure of $47 \mathrm{mmHg}$. The interatrial septum revealed a patent foramen ovale with right-to-left shunt after injection of agitated saline; therefore, we installed air-bubble filters on all $i v$ lines.

Thirty minutes after induction, a slight decrease in $\mathrm{PaO}_{2}$ was noticed; we increased the PEEP to $15 \mathrm{~cm}$ $\mathrm{H}_{2} \mathrm{O}$ without hemodynamic consequences. The intraoperative hemodynamic course was stable; blood pressures were in the $115-140 / 50-70 \mathrm{mmHg}$ range, and heart rate between 60 and 100 beats. $\mathrm{min}^{-1}$. The endtidal concentration of isoflurane, titrated to maintain blood pressure and heart rate within $20 \%$ of preoperative baseline, ranged between $1.3 \%$ and $0.9 \%$ initially, and averaged $0.6 \%$ [ 0.5 minimal alveolar concentration (MAC)] during the last two hours of this six-hour operation. The arterial oxygenation remained stable: $\mathrm{PaO}_{2}$ between 100 and $160 \mathrm{mmHg}$ on $\mathrm{FIO}_{2} 0.4$ to 0.6 and $15 \mathrm{~cm} \mathrm{H}_{2} \mathrm{O}$ PEEP. Throughout the operation we continuously monitored $\mathrm{PaCO}_{2}$ which was maintained at around $40 \mathrm{mmHg}$ with the end-tidal $\mathrm{CO}_{2}$ in the 35 to $38 \mathrm{mmHg}$ range. We were able to decrease the $\mathrm{FIO}_{2}$ to 0.4 toward the last third of the operation. Respiratory system compliance $($ compliance $=$ TV $/$ PIP-PEEP $)$ remained unchanged throughout operation.

Total fluids administered during the operation were $10 \mathrm{~L}$ of crystalloids and $4 \mathrm{~L}$ of colloids; the estimated blood loss was $1 \mathrm{~L}$. Throughout the operation muscle relaxation was achieved by titrating vecuronium (total of $30 \mathrm{mg}$ ) and pancuronium (total of $60 \mathrm{mg}$ ) to maintain two ulnar nerve (adductor pollicis) train-of-four twitches. At the end of the operation muscle relaxation was reversed. Before the administration of the reversal agent, the patient had two train-of-four twitches; ten minutes later $50 \mathrm{~Hz}$ tetanic stimulation achieved a sustained tetanic contracture on the adductor pollicis muscle. When the patient was transferred from the operating room table to a specially designed hospital bed, he opened his eyes spontaneously, fully followed commands, had good hand strength, and used head movements to answer questions. He denied pain, and his only complaint was the presence of the endotracheal tube. No opioid was given before emergence. The continuous blood gas monitor showed a $\mathrm{PaCO}_{2}$ of $69 \mathrm{mmHg}$ during spontaneous breathing with a TV of $200 \mathrm{~mL}$, which we considered inadequate for tracheal extubation; therefore, the patient was sedated with $4 \mathrm{mg}$ of midazolam, the dexmedetomidine infusion was continued, and he was transferred to the intensive care unit (ICU) with the endotracheal tube in place. Due to the patient's extreme obesity, the critical care team conducted a gradual weaning from mechanical ventilation, first with synchronized intermittent mandatory ventilation $\mathrm{FIO}_{2}$ of 0.4 , respiratory rate 15 breaths. $\mathrm{min}^{-1}$, TV $800 \mathrm{~mL}$, PEEP $15 \mathrm{~cm}$ $\mathrm{H}_{2} \mathrm{O}$, pressure support $20 \mathrm{~cm} \mathrm{H}_{2} \mathrm{O}$, PIP $32 \mathrm{~cm} \mathrm{H}_{2} \mathrm{O}$ ), followed by CPAP $\left(\mathrm{FIO}_{2}\right.$ 0.4, respiratory rate 8-16 breaths. $\mathrm{min}^{-1}$; TV $800 \mathrm{~mL}$, PEEP $15 \mathrm{~cm} \mathrm{H} \mathrm{H}_{2} \mathrm{O}$; pressure support 20 to $8 \mathrm{~cm} \mathrm{H}_{2} \mathrm{O}$ ). The tracheal extubation was postponed until the next morning despite clinically adequate breathing through the night evidenced by adequate respiratory rate $\left(25\right.$ breaths $\left.\cdot \mathrm{min}^{-1}\right)$, good oxygenation $\left(\mathrm{PaO}_{2} 135 \mathrm{mmHg}\right.$ on $\mathrm{FIO}_{2}$ of 0.4$)$, adequate ventilation $\left(\mathrm{PaCO}_{2}\right.$ of $\left.40 \mathrm{mmHg}\right)$, and good muscle strength as evidenced by sustained head-lift test. During the first eight postoperative hours, the patient received $100 \mu \mathrm{g}$ of fentanyl $(50 \mu \mathrm{g}$ bolus twice) and 8 $\mathrm{mg}$ of midazolam in divided doses.

Visual analogue scale scores (VAS; range 0-10 where 0 is "no pain" and 10 is the "worst pain imaginable," typically taken either on an hourly basis or before initiation of any pain treatment) and recorded by the ICU nurses through the night, ranged from 4 to 6 (median score was 5 ). At the time of tracheal extubation, the VAS score was 4. During the first postoperative day, VAS scores ranged from 3 to 6 (median score of 4 ), and throughout that period he self-administered $48 \mathrm{mg}$ of morphine via patient controlled analgesia (PCA), in addition to the continuous dexmedetomidine infusion. After $24 \mathrm{hr}$, the dexmedetomidine infusion was stopped, and during the second $24 \mathrm{hr}$ period, the patient received a total of $148 \mathrm{mg}$ of PCA morphine with VAS scores ranging from 0 to 4 (median score of 0 ). During an uneventful hospital stay, the patient lost $58.5 \mathrm{~kg}$, most of which was lymphedema treated actively by compressive garments and diuretics. The patient had no complaints regarding any aspect of analgesia/anesthesia management. On postoperative day 15 , he was transferred to another special care facility for continued care. One month postoperatively his weight was 325 $\mathrm{kg}$ (down $108 \mathrm{~kg}$ ).

\section{Discussion}

Ten percent of morbidly obese patients have severe respiratory impairment such as obesity hypoventilation syndrome, ${ }^{1}$ while over $50 \%$ have moderate or severe sleep apnea. ${ }^{5}$ While epidural analgesia can be an excellent alternative for perioperative pain management, technical difficulties and patient refusal may limit its use, particularly in the morbidly obese patient population. Opioids can be associated with potentially pronounced respiratory depressant effects in 
patients with OSA. Therefore, this patient population could benefit from a drug that can produce analgesic effects without significant or long-lasting effects on respiratory function.

The analgesic properties of $\alpha_{2}$-adrenergic agonists were first described in 1974, when nociceptive thresholds in rats given clonidine were noted to be increased. ${ }^{6}$ About the same time, lack of respiratory depression with the $\alpha_{2}$-adrenergic agonist clonidine was reported. ${ }^{7}$ Consequently, the development of dexmedetomidine, a highly specific $\alpha_{2}$-adrenergic agonist with an eight times higher affinity for the $\alpha_{2}$-adrenoceptor than clonidine, produced a class of sedative/analgesic drugs that could have advantages for the perioperative management of the obese patient. Dexmedetomidine, with sedative/hypnotic, anesthetic-sparing, analgesic, and sympatholytic properties, has been approved for use in the management of patients in the ICU ${ }^{8,9}$ however, its role in contemporary intraoperative anesthesia practice has not yet been established.

Dexmedetomidine stimulates $\alpha_{2}$-adrenergic receptors and couples in an inhibitory fashion to the L-type calcium channels. These effects differ depending on receptor location; in the locus ceruleus, this stimulation provides sedation, while in the spinal cord it enhances analgesia. ${ }^{9}$ Because $\alpha_{2}$-agonists may produce transient hypertension at higher doses (via activation of $\alpha_{2 B}$ adrenoceptor located on smooth muscle cells in the resistance vessels), ${ }^{10}$ slow $i v$ loading over ten to $20 \mathrm{~min}$ is recommended to minimize the effects on heart rate and blood pressure (at lower doses the dominant action is an $\alpha_{2}$-agonist-induced sympatholysis by decreasing sympathetic outflow through central $\alpha_{2 \mathrm{~A}}$-stimulation). ${ }^{9}, 11$ A continuous infusion maintains a unique level of sedation (patients appear to be asleep, but are readily arousable) as well as an analgesic-sparing effect without affecting respiration. ${ }^{4}$ Venn et al. ${ }^{4}$ demonstrated that, when used in spontaneously breathing patients in the ICU after surgery, dexmedetomidine reduced morphine requirements by over $50 \%$ while at the same time had no effect on respiratory rate, hemoglobin saturation, arterial $\mathrm{pH}$, and $\mathrm{PaCO}_{2}$. Interestingly the $\mathrm{PaO}_{2}: \mathrm{FIO}_{2}$ ratios were statistically higher in the dexmedetomidine group compared to patients receiving morphine and midazolam boluses.

Animal data report different effects of dexmedetomidine on ventilation. In dogs, dexmedetomidine causes an increase in minute ventilation, a decreased response to inhaled $\mathrm{CO}_{2}$ without change in arterial blood gases. ${ }^{12}$ In rabbits, dexmedetomidine induced a dose-dependent reduction in respiratory rate and $\mathrm{PaO}_{2}$ and an increase in arterial $\mathrm{PaCO}_{2}{ }^{13}$ In humans, the infusion of dexmedetomidine causes a mild decrease in minute ventilation and an increase in $\mathrm{PaCO}_{2}{ }^{14}$ All these effects are much less pronounced than those of opioids and other $i v$ and volatile anesthetic agents, and appear to be similar in order of magnitude to those seen during profound sleep.

The patient described was coherently responsive soon after discontinuation of isoflurane; however, immediate postoperative hypoventilation (evidenced by a $\mathrm{PaCO}_{2}$ of $69 \mathrm{mmHg}$ ) delayed tracheal extubation. This hypoventilation can be explained by both the depressant effects of residual isoflurane and/or the direct inhibition of diaphragmatic activity by upper abdominal surgical manipulation. ${ }^{15,16}$ The patient was subjected to gradual weaning from mechanical ventilation and, the following morning, after tracheal extubation, he required only the administration of oxygen via a face mask followed by nasal cannula to maintain an adequate $\mathrm{SaO}_{2}$ throughout his ICU stay.

The analgesic effects of dexmedetomidine have been demonstrated in numerous studies. When infused at rates of 0.2 and $0.7 \mu \mathrm{g} \cdot \mathrm{kg}^{-1} \cdot \mathrm{hr}^{-1}$, dexmedetomidine produced clinically effective sedation and reduced the analgesic requirements of ventilated ICU patients. ${ }^{17}$ There was no clinically apparent respiratory depression after cessation of assisted ventilation, while at the same time dexmedetomidine maintained a high degree of patient arousability. ${ }^{17}$ Aho et al. ${ }^{18}$ showed that, after laparoscopic tubal ligation, dexmedetomidine relieved pain and reduced opioid requirements. In a subsequent study, ${ }^{19}$ the same authors confirmed that dexmedetomidine infusion diminished isoflurane requirement by $>90 \%$. Similarly, in animal studies, a reduction of halothane requirements of up to $90 \%$ was demonstrated. ${ }^{20,21}$ In this patient, we titrated the inhalational anesthetic to maintain blood pressure and heart rate close to preoperative values; by the last third of the operation this objective was achieved with only 0.5 MAC of anesthesia (isoflurane only). When used in the ICU setting and given to intubated patients, dexmedetomidine resulted in $80 \%$ less use of midazolam, and $50 \%$ less use of morphine compared with the control group. ${ }^{22}$ In another study, dexmedetomidine reduced propofol requirements during bispectral index-guided sedation in the ICU and reduced morphine requirements by over $50 \%{ }^{23}$ The patient described required $48 \mathrm{mg}$ of morphine during the first postoperative day via PCA (while still receiving a dexmedetomidine infusion). During the second $24 \mathrm{hr}$ postoperatively, after dexmedetomidine was stopped, his PCA morphine use increased to $148 \mathrm{mg}$ over $24 \mathrm{hr}$. This major increase in morphine use with modest changes in pain scores during the second postoperative day (when one 
would expect the patient to have less pain) strongly supports the presence of a dexmedetomidine-induced narcotic-sparing effect. This is in agreement with the recent report by Arain et al. ${ }^{24}$ who demonstrated a $66 \%$ reduction of postoperative morphine requirements when using dexmedetomidine.

In conclusion, we report a morbidly obese patient whose intraoperative narcotic management was substituted entirely with dexmedetomidine. The narcoticsparing effects of dexmedetomidine were evident both intraoperatively (low isoflurane requirements) and postoperatively (lower total dose of self-administered PCA morphine). This novel drug application could become a useful anesthesia adjunct for patients susceptible to narcotic-induced respiratory depression and especially so in the morbidly obese.

\section{References}

1 Sugerman HJ. Pulmonary function in morbid obesity. Gastroenterol Clin North Am 1987; 16: 25-37.

2 Hall JE, Uhrich TD, Barney JA, Arain SR, Ebert TJ. Sedative, amnestic, and analgesic properties of smalldose dexmedetomidine infusions. Anesth Analg 2000; 90: 699-705.

3 Bradley C. Dexmedetomidine--a novel sedative for postoperative sedation. Intensive Crit Care Nurs 2000; 16: 328-9.

4 Venn RM, Hell J, Grounds RM. Respiratory effects of dexmedetomidine in the surgical patient requiring intensive care. Crit Care 2000; 4: 302-8.

5 Resta O, Foschino-Barbaro MP, Legari G, et al. Sleeprelated breathing disorders, loud snoring and excessive daytime sleepiness in obese subjects. Int J Obesity 2001; 25: 669-75.

6 Paalzow L. Analgesia produced by clonidine in mice and rats. J Pharm Pharmacol 1974; 26: 361-3.

7 Maxwell GM. The effects of 2-(2,6-dichlorphenylamine)-2-imidazoline hydrochloride (Catapres $\left.{ }^{\circledR}\right)$ upon the systemic and coronary haemodynamics and metabolism of intact dogs. Arch Int Pharmacodyn Ther 1969; 181: 7-14.

8 Mizobe T. Adrenergic receptor and alpha 2 agonist--4: applied and clinical pharmacology of alpha 2 agonist (Japanese). Masui 1997; 46: 1066-70.

9 Kamibayashi T, Maze M. Clinical uses of alpha 2 -adrenergic agonists. Anesthesiology 2000; 93: 1345-9.

10 Bloor BC, Ward DS, Belleville JP, Maze M. Effects of intravenous dexmedetomidine in humans. II. Hemodynamic changes. Anesthesiology 1992; 77: 1134-42.

11 Coursin DB, Coursin DB, Maccioli GA.

Dexmedetomidine. Curr Opin Crit Care 2001; 7: 221-6.
12 Bloor BC, Abdul-Rasool I, Temp J, Jenkins S, Valcke C, Ward DS. The effects of medetomidine, an $\alpha_{2}$-adrenergic agonist, on ventilatory drive in the dog. Acta Vet Scand Suppl 1989; 85: 65-70.

13 Jarvis DA, Duncan SR, Segal IS, Maze M. Ventilatory effects of clonidine alone and in the presence of alfentanil, in human volunteers. Anesthesiology 1992; 76: 899-905.

14 Belleville JP, Ward DS, Bloor BC, Maze M. Effects of intravenous dexmedetomidine in humans. I. Sedation, ventilation, and metabolic rate. Anesthesiology 1992; 77: 1125-33.

15 Erice F, Fox GS, Salib YM, Romano E, Meakins JL, Magder SA. Diaphragmatic function before and after laparoscopic cholecystectomy. Anesthesiology 1993; 79: 966-75; discussion 27A-8A.

16 Sharma RR, Axelsson H, Oberg A, et al. Diaphragmatic activity after laparoscopic cholecystectomy.

Anesthesiology 1999; 91: 406-13.

17 Bhana N, Goa KL, McClellan KJ. Dexmedetomidine. Drugs 2000; 59: 263-8; discussion 269-70.

18 Aho MS, Erkola OA, Scheinin H, Lehtinen AM, Korttila $K T$. Effect of intravenously administered dexmedetomidine on pain after laparoscopic tubal ligation. Anesth Analg 1991; 73: 112-8.

19 Aho M, Erkola O, Kallio A, Scheinin H, Korttila K. Dexmedetomidine infusion for maintenance of anesthesia in patients undergoing abdominal hysterectomy. Anesth Analg 1992; 75: 940-6.

20 Segal IS, Vickery RG, Walton JK, Doze VA, Maze M. Dexmedetomidine diminishes halothane anesthetic requirements in rats through a postsynaptic alpha adrenergic receptor. Anesthesiology 1988; 69: 818-23.

21 Vickery RG, Sheridan BC, Segal IS, Maze M. Anesthetic and hemodynamic effects of the stereoisomers of medetomidine, an $\alpha_{2}$-adrenergic agonist, in halothaneanesthetized dogs. Anesth Analg 1988; 67: 611-5.

22 Venn RM, Bradshaw CJ, Spencer R, et al. Preliminary UK experience of dexmedetomidine, a novel agent for postoperative sedation in the intensive care unit. Anaesthesia 1999; 54: 1136-42.

23 Triltsch $A E$, Welte $M$, von Homeyer $P$, et al. Bispectral index-guided sedation with dexmedetomidine in intensive care: a prospective, randomized, double blind, placebo-controlled phase II study. Crit Care Med 2002; 30: 1007-14.

24 Arain SR, Rueblow RM, Ubrich TD, Ebert TJ. The efficacy of dexmedetomidine versus morphine for postoperative analgesia after major inpatient surgery. Anesth Analg 2004; 98: 153-8. 